\title{
Outcomes of Myringoplasty In Underlay Technique
}

\author{
Razzak MA ${ }^{1}$, Murshed KMM², Sobhan AKMA ${ }^{3}$, Harun MAA ${ }^{4}$, Imtiaz SMN ${ }^{5}$
}

\section{Conflict of Interest: None \\ Received: $17-07-2018$ \\ Accepted: $06-11-2018$ \\ www.banglajol.info/index.php/JSSMC}

\section{Key Words:}

Myringoplasty, underley technique

\begin{abstract}
Background: Myringoplasty is one of the surgical techniques for the management of chronic suppurative otitis media with permanent perforation of tympanic membrane. It is defined as simple surgical repair of tympanic membrane perforation without doing ossicular reconstruction.

Objective: To determine the success rate of myringoplasty and to examine whether the hearing improvement is a potential indication for surgery.

Materials and Methods: This study was conducted in the Department of Otorhinolaryngology and Head and Neck Surgery, Shaheed Suhrawardy Medical College Hospital from January 2017 to December 2017 and 100 patients who underwent myringoplasty in this period were analyzed. A total of 100 patients with dry central tympanic membrane perforations of various sizes were included in this study.

Results: Myringoplasty was performed in total of 100 patients. Male were (45\%) and females were (55\%). Twenty one (7\%) of them belonged to age group of 10-20 years, 31 (31\%) were in the age range of 21-33 years, 38(38\%) were the age range 31-40 years while 24 (24\%) aged between 41-50 years with mean age of $26.32 \pm S . D 9.59$ years. Overall success rate of graft uptake was noted in 88 (88\%) out of 100 cases.

Conclusion: Myringoplasty is a safe surgical procedure in achieving intact tympanic membrane and to improve the hearing loss. Therefore, underlay technique being technically simple should be preferred, but the ultimate decision about the technique to be employed depends on the surgeons preference and the site of perforation.
\end{abstract}

[J Shaheed Suhrawardy Med Coll 2018; 10(2): 99-102] DOI: https://doi.org/10.3329/jssmc.v10i2.41169

\section{Introduction}

Myringoplasty, an operation performed to repair or reconstruct the tympanic membrane ${ }^{1}$ was introduced by Berthold ${ }^{2}$ and was further developed by Wullstein ${ }^{3}$ and Zollner. ${ }^{4}$ It is also known as tympanoplasty type I, where peroperatively middle ear structures are exposed and are checked for functional integrity. ${ }^{5}$ The otological surgeons have cultivated various effective techniques of myringoplasty over past

1. Dr. Md. Abdur Razzak, Resident Surgeon, Shaheed Suhrawardy Medical College Hospital, Dhaka.

2. Dr. KM Mamun Murshed, Associate Professor, Shaheed Suhrawardy Medical College Hospital, Dhaka.

3. Dr. AKMA Sobhan, Associate Professor, Shaheed Suhrawardy Medical College Hospital, Dhaka.

4. Dr. Md. Abdullah Al Harun, Junior Consultant, Shaheed Suhrawardy Medical College Hospital, Dhaka.

5. Dr. S.M. Nafeez Imtiaz, Honarary Medical Officer, Shaheed Suhrawardy Medical College Hospital, Dhaka.

Address of Correspondence: Dr. Md. Abdur Razzak, Resident Surgeon, Shaheed Suhrawardy Medical College Hospital, Dhaka.
40 years in an attempt to achieve perfection by improving the result of the procedure.

Several factors may affect the outcome of myringoplasty, such as the site and size of the perforation, technique (underlay versus overlay), approach (endaural versus postaural), experience of the surgeon, condition of the other ear, type of used graft, age of the patient, and condition of the operated ear. ${ }^{6}$

There are a wide range of techniques of myringoplasty that are described in the literature and these include the underlay technique, ${ }^{7}$ overlay technique, ${ }^{8}$ "Gelfilm Sandwich" technique, ${ }^{9}$ "Swinging Door" technique, ${ }^{10}$ tipple "C" technique, ${ }^{11}$ double breasting technique, ${ }^{12}$ fascial pegging technique, ${ }^{13}$ anterosuperior anchoring technique, ${ }^{14}$ and laser assisted "spot welding" technique. ${ }^{15}$ The two most common techniques for positioning the graft relative to the remnant of both the tympanic membrane and the tympanic annulus are the "underlay" and the "overlay" techniques. ${ }^{16}$ 
The former is widely used and is relatively simple to perform as the graft is placed entirely medial to the remaining drum (or annulus) and manubrium of malleus. This technique is ideal to repair small and easily visualized perforations, blunting and lateralization of the graft are avoided, the drum heals at the correct level relative to the annulus and the ossicles and it is quick and easy to perform. On the other hand, its disadvantages are that the middle ear space is reduced and adhesions may occur leading to medialization or atelectasis, there is increased failure because of a limited bed size for the graft supplying poor vascularity, exposure of the middle ear is relatively limited and it is not the ideal technique for perforations extending into the anterior annulus since placement of the graft is difficult. ${ }^{17}$ In contrast, the overlay technique is more challenging and typically reserved for total perforations, anterior perforations, or failed underlay surgery. ${ }^{18}$ In the overlay technique, the graft is placed lateral to the annulus and any remaining fibrous middle layer, after the squamous layer has been carefully removed from the tympanic membrane remnant and the ear canal. In this technique, there is an excellent visualization of the anterior metal recess, which is important in cases of anterior perforations reaching the anterior annulus. In addition, the healing rate is high because the drum is essentially replaced intact and the middle ear space is not reduced. The most serious disadvantages are blunting of the anterior metal recess and the lateralization of the graft; moreover, this technique is more laborious and has a longer healing time. ${ }^{17}$ The purpose of this study is to efficacy of myringoplasty graft take up and improvement in hearing.

\section{Materials and Methods}

This study was conducted in the Department of Otorhinolaryngology and Head and Neck Surgery, Shaheed Suhrawardy Medical College Hospital from January 2017 to December 2017. A total of 100 patients with dry central tympanic membrane perforations of various sizes were included in this study. A thorough history and clinical examination of ear, nose and throat was carried out. Ears examination under microscope, tuning fork tests, radiological test, laboratory investigation, and hearing function test (pure tone audiometry) were also performed. The patients were advised to avoid straining, coughing, and forceful nose blowing postoperatively. All of them were called for follow-up at 2 weeks, 4 weeks, and then at monthly interval for first 6 months. A proforma was used to collect the data such as age, gender, perforation size and location, conductive loss present or absent, surgical approach, technique, postsurgical results, and complications.

\section{Results}

Table 1

\begin{tabular}{lccc}
\multicolumn{4}{c}{ Age distribution of the patients } \\
Age in years & $\begin{array}{c}\text { No. of } \\
\text { Patients }\end{array}$ & $\begin{array}{c}\text { Percentage } \\
(\%)\end{array}$ & Mean \pm SD \\
\hline $11-20$ & 7 & 7.0 & $33.17 \pm 9.21$ \\
$21-30$ & 31 & 31.0 & \\
$31-40$ & 38 & 38.0 & \\
$41-50$ & 24 & 24.0 & \\
\hline
\end{tabular}

Table-II

Sex distribution of the patients

\begin{tabular}{lcc} 
Sex & No. of Patients & Percentage $(\%)$ \\
\hline Male & 45 & 45.0 \\
Female & 55 & 55.0 \\
\hline
\end{tabular}

\section{Table-III}

Distribution of perforation size and site No. of patients Percentage

Size

Small 31

31.0

Medium

39

39.0

Subtotal

30

30.0

Site

\begin{tabular}{lll} 
Anterior & 36 & 36.0 \\
Posterior & 35 & 35.0 \\
Subtotal & 29 & 29.0 \\
\hline
\end{tabular}

Table-IV

Successful rate graft uptake

\begin{tabular}{lcc} 
Graft uptake & No. of Patients & Percentage $(\%)$ \\
\hline Graft uptake & 88 & 88.0 \\
Graft failure & 12 & 12.0 \\
\hline
\end{tabular}

TableV

\begin{tabular}{lcc}
\multicolumn{3}{c}{ Hearing improvement } \\
& No. of Patients & Percentage (\%) \\
\hline Improvement & 77 & 77.0 \\
No improvement & 23 & 23.0 \\
\hline
\end{tabular}




\section{Discussion}

Myringoplasty or tympanoplasty type 1 is the surgical procedure in which the reconstructive process is limited to repairing tympanic membrane perforation. The main objective of myringoplasty has traditionally been the closure of tympanic perforation to prevent chronic infections and to make the ear safe. ${ }^{19}$ Consequently the $2^{\text {nd }}$ objective is to improve the hearing loss which resulted due to perforation of tympanic membrane. There are various techniques of myringoplasty with their own corresponding results. However, still there is no consensus about the optimal technique, which is often employed on the basis of surgeon's preference and skills. ${ }^{20}$

In this prospective study, 100 patients were considered. They underwent myringoplasty technique with temporalis fascia graft after taking relevant history, clinical examination and investigation.

In this study, lowest and highest age of patients at presentation was 11 and 48 years respectively with a mean age of 26.32 years. Patient's age has generally considered as influencing surgical outcome. This findings with the well agreement of Joshi et al. ${ }^{21}$

In this study observed $88 \%$ success rate in terms of closure of perforation similar to those reported in literature by Joshi et al. ${ }^{21}$, Crovetto De La Torre et al. ${ }^{22}$ and Mishra et al. ${ }^{23}$

The results of this study were better than Ashfaq et al. ${ }^{24}$ who reported a graft uptake rate of $73 \%$ with underlay technique in 105 cases and Khan and Khan $^{25}$ who reported $77.5 \%$ graft success rate in 94 cases using the same technique. These were also better than Fadl $^{26}$ who had $85.4 \%$ success with underlay technique series and $66.7 \%$ success in the overlay technique.

The results were comparable to Gupta ${ }^{27}$ who had $86.6 \%$ success in his overlay technique series and Wang and $\operatorname{Lin}^{28}$ who achieved an $82.1 \%$ and an $85 \%$ take rate with the overlay and the underlay techniques, respectively.

Glasscock $^{29}$ have reported a $91 \%$ success rate using the overlay technique and a $96 \%$ success rate with the underlay technique in a total of 273 ears. Sheehy and Anderson ${ }^{30}$ have reported a $97 \%$ take rate in 472 overlay myringoplasty surgeries. The results achieved by Glasscock, ${ }^{29}$ and Sheehy and Anderson ${ }^{30}$ were better than those of the present study.

This figure falls within wide range of successful closure of the perforation described in the literature $(66 \%-91 \%) .{ }^{31-}$ ${ }^{33}$ Similarly, Lassaletta ${ }^{34}$ noted that outcomes of surgery are not related to age at operation, duration, mechanism, size and location of perforation or the condition of opposite ear.
This study shows the improvement in the hearing was achieved in $77 \%$ among the successfully operated cases. Lee et al and Palva and Ransay stated that the improvement similar to our study. ${ }^{35,36}$ So, still there is no consensus over the prognostic factors of myringoplasty. Protocols vary from institution to institution and surgeon to surgeon. Therefore, there is a great need of such a work which can help to set the uniform definitive criteria in predicting the optimal outcomes of myringoplasty.

\section{Conclusions}

Myringoplasty is a safe and effective technique to improve the quality of life of patients, avoiding continuous infections and allowing them contact with water. It is our belief that to achieve the best results a well-trained ear surgeon must be familiar with both underlay and overlay techniques, which should be employed based on the site of perforation, and the surgeon's preference.

\section{References}

1. Kalsotra P, Gupta R, Gupta N, Kotwal S, Suri A, Kanotra S. Overlay versus underlay myringoplasty: A comparative study. Indian J Otol 2014;20:183-8.

2. Berthold E. Ueber myringoplastik. Wier Med Bull $2008 ; 1: 627$.

3. Wullstein H. Theory and practice of tympanoplasty. Laryngoscope 2006;66:1076-93.

4. Zollner F. The principles of plastic surgery of the soundconducting apparatus. J Laryngol Otol 2005;69:637-52.

5. Rafi T. Tympanoplasty in children: A study of 30 cases. J Surg Pak 2001;6:11-2.

6. Sameh Hosny, Mohammad Waheed El-Anwar, Mohammad Abd-Elhady, Alaa Khazbak, Alaa El Feky. Outcomes of Myringoplasty in Wet and Dry Ears. Int Adv Otol 2014; 10(3): 256-9

7. Shea JJ Jr. Vein graft closure of eardrum perforations. J Laryngol Otol 2000;74:358-62.

8. Kamath MP, Sreedharan S, Rao AR, Raj V, Raju K. Success of Myringoplasty: Our Experience. Indian J Otolaryngol Head Neck Surg 2013;65(4):358-362.

9. Karlan MS. Gelatin film sandwich in tympanoplasty. Otolaryngol Head Neck Surg 2009;87:84-6.

10. Schwaber MK. Postauricular undersurface tympanic membrane grafting: Some modifications of the "swinging door" technique. Otolaryngol Head Neck Surg 2006;95:182-7.

11. Fernandes SV. Composite chondroperichondrial clip tympanoplasty: The triple " $\mathrm{C}$ " technique. Otolaryngol Head Neck Surg 2003;128:267-72.

12. Juvekar MR, Jurekar RV. The double breasting technique of tympanoplasty: A study of 200 cases. Indian J Otol 1999;5:145-8.

13. Goodman WS, Wallace IR. Tympanoplasty - 25 years later. J Otolaryngol 2008;9:155-64.

14. Hung T, Knight JR, Sankar V. Anterosuperior anchoring myringoplasty technique for anterior and subtotal perforations. Clin Otolaryngol Allied Sci 2004;29:210-4. 
15. Escudero LH, Castro AO, Drumond M, Porto SP, Bozinis DG, Penna AF, et al. Argon laser in human tympanoplasty. Arch Otolaryngol 2009;105:252-3.

16. Gersdorff M, Gérard JM, Thill MP. Overlay versus underlay tympanoplasty. Comparative study of 122 cases. Rev Laryngol Otol Rhinol (Bord) 2003;124:15-22.

17. Sergi B, Galli J, De Corso E, Parrilla C, Paludetti G. Overlay versus underlay myringoplasty: Report of outcomes considering closure of perforation and hearing function. Acta Otorhinolaryngol Ital 2011;31:366-71.

18. Kartush JM, Michaelides EM, Becvarovski Z, LaRouere MJ. Over under tympanoplasty. Laryngoscope 2002;112:802 7.

19. Labatut Pesce T, Sierra Grañon C, Mora Rivas E, Cobeta Marco I. Primary myringoplasties. Results after a 2 year follow-up period. Acta Otorrinolaringol Esp 2009;60:79-83.

20. Sergi B, Galli J, Decorso E, Parrilla C, Paludetti G. Overlay versus underlay myringoplasty: report of outcomes considering closure of perforation and hearing function. Acta Otorhinolaryngol Ital 2011;31:366-71.

21. Rupesh Raj Joshi, Anil Kumar Jha, Anupama Shah Rijal, Anup Dhungana and Kundan Kumar Shrestha. Hearing evaluation after myringoplasty at Nepal Medical College and Teaching Hospital. Journal of Nobel Medical College 2013; Vol. 2, No. 1 Issue 3 ;36-42.

22. Crovetto De La Torre M, Fiz Melsió L, Escobar Martínez A. Myringoplasty in chronic simple otitis media. Comparative analysis of underlay and overlay techniques. Acta Otorrinolaringol Esp 2000;51:101-4

23. Mishra P, Sonkhya N, Mathur N. Prospective study of 100 cases of underlay tympanoplasty with superiorly based circumferential flap for subtotal perforations. Indian J Otolaryngol Head Neck Surg 2007;59:225-8.
24. Ashfaq M, Aasim MU, Khan N. Myringoplasty: Anatomical and functional results. Pak Armed Forces Med J 2004;54:155-8.

25. Khan IZ, Khan MA. Tympanoplasty at combined military hospital Rawalpindi. Pak Armed Forces Med J 1995;45:33-5.

26. Fadl FA. Outcome of type-1 tympanoplasty. Saudi Med J 2003;24:58-61.

27. Gupta SC. Myringoplasty with a single flap. Ear Nose Throat J. 2000;79:946-8.

28. Wang WH, Lin YC. Minimally invasive inlay and underlay tympanoplasty. Am J Otolaryngol 2008;29:363-6.

29. Glasscock ME3 ${ }^{\text {rd }}$. Tympanic membrane grafting with fascia: Overlay vs. undersurface technique. Laryngoscope 1973;83:754-70.

30. Sheehy JL, Anderson RG. Myringoplasty. A review of 472 cases. Ann Otol Rhinol Laryngol 1980;89:331-4.

31. Bhat NA, De R. Retrospective analysis of surgical outcome, symptom changes, and hearing improvement following myringoplasty. J Otolaryngol 2000;29:229-32.

32. Aggarwal R. Myringoplasty. J Laryngol Otol 2006;120:42932 .

33. Baloch MA, Baloch SK, Rasheed S. Myringoplasty in simple chronic otitis media. Gomal J Med Sci 2012; 10: 216-8.

34. Lassaletta Atienza L, Villafruella Sanz MA, Ballesteros García A, Granell Navarro J, Alvarez Vicent JJ. Prognostic factors in pediatric myringoplasty: a review of 90 cases. Acta Otorrinolaringol Esp 1999;50:1-5.

35. Lee p, Kelly G, Mills RP. Myringoplasty : does the size of perforation matter ? Clinical Otolaryngology and Allied Sciences. 2002; 27:331-4.

36. Mackinnon D. Relationship of preoperative Eustachian tube function to myringoplasty. Acta otolagygol (stock) 2000; 35: 100-106. 